\title{
Mechanical Properties of Polypropylene/Calcium Carbonate Nanocomposites
}

\author{
Daniel Eiras ${ }^{\mathrm{a} *}$, Luiz Antonio Pessan ${ }^{\mathrm{b}}$ \\ aPPG-CEM/DEMa, Universidade Federal de São Carlos - UFSCar \\ ${ }^{\mathrm{b}}$ DEMa, Universidade Federal de São Carlos - UFSCar
}

Received: September 17, 2009; Revised: November 20, 2009

\begin{abstract}
The aim of this work was to study the influence of calcium carbonate nanoparticles in both tensile and impact mechanical properties of a polypropylene homopolymer. Four compositions of $\mathrm{PP} / \mathrm{CaCO}$ nanocomposites were prepared in a co-rotational twin screw extruder machine with calcium carbonate content of 3, 5, 7 and $10 \mathrm{wt}$. (\%) The tests included SEM analyzes together with EDS analyzer and FTIR spectroscopy for calcium carbonate, tensile and impact tests for PP and the nanocomposites. The results showed an increase in PP elastic modulus and a little increase in yield stress. Brittle-to-ductile transition temperature was reduced and the impact resistance increased with the addition of nanoparticles. From the stress-strain curves we determined the occurrence of debonding process before yielding leading to stress softening. Debonding stress was determined from stress-strain curves corresponding to stress in $1 \%$ strain. We concluded that the tensile properties depend on the surface contact area of nanoparticles and on their dispersion. Finally we believe that the toughening was due to the formation of diffuse shear because of debonding process.
\end{abstract}

Keywords: toughening, nanocomposites, calcium carbonate, debonding

\section{Introduction}

Polypropylene is a semicrystalline polymer that exhibits very attractive mechanical properties, like ductility and strength at room temperature or under moderate rates of deformation ${ }^{1}$. However, under severe conditions it becomes brittle. This behavior makes it interesting for commercial and scientific fields to study methods for toughening these materials.

In order to increase the impact strength of semicrystalline polymers the incorporation of elastomeric particles has been widely used with great increases in the impact resistance, but accompanied of losses in the elastic modulus ${ }^{2}$. An alternative for the incorporation of elastomeric particles is the incorporation of debonding rigid particles which are able to increase the impact resistance with the advantage of increase the elastic modulus of the matrix ${ }^{2,3}$. In this context, the incorporation of nanoparticles have been attracted much interesting in scientific field because of the possibility of use low contents of fillers with great increases in both impact and tensile mechanical properties ${ }^{4,5,6,7}$.

The main mechanism of toughening semicrystalline polymers with the addition of inorganic fillers has been extensively discussed and involves stress concentration, debonding of the polymer/filler interface and the formation of shear bands ${ }^{3,7}$. First, the inorganic filler act as stress concentrator in the matrix during deformation due to the difference between the elastic behavior of the phases, i.e., the different elastic modulus of each phase. Due to the stress concentration effect, a triaxial state of stress is presented around the particle. The debonding of the interface releases this state of stress making it plane and facilitating yielding of polymeric chains. Finally, shear bands which are intrinsic deformation mechanisms of polymeric materials are created leading to higher energy absorption during deformation Figure $1^{3,7}$.

Several authors discussed the occurrence of debonding in literature, and tried to determine the moment in which debonding starts, i.e. before or at yielding point ${ }^{6,18}$. Moreover some authors discussed the possibility of partial debonding which means that debonding proc- ess starts before yielding when just one pole of the particle and ends near rupture ${ }^{23}$. The most common methods described in literature to study debonding and determine its occurrence are acoustic emission analyses and tensile dilatometry. In the first method ultrasound signals emitted by the debonding process are recorded during tensile tests and provide a cumulative curve in which the occurrence of debonding is easy to determine because of the great increase in the number of signals ${ }^{18}$. The second method involves the use of two extensometers to measure both axial and longitudinal deformation of the samples and calculate volume strain. Assuming that the volume strain in neat polymer is the same of that of the polymer in the composite it's possible to calculate the volume strain due to debonding according to the following Equation 1, where $\left(\Delta \mathrm{V} / \mathrm{V}_{\mathrm{o}}\right)_{\mathrm{C}}$ is the volume strain of the composite, $\left(\Delta \mathrm{V} / \mathrm{V}_{\mathrm{o}}\right)_{\mathrm{M}}$ is the volume strain of the polymer matrix, $\left(\Delta \mathrm{V} / \mathrm{V}_{\mathrm{o}}\right)_{\mathrm{V}}$ is the volume strain due to the debonding process and $\phi$ is the volume fraction of the filler ${ }^{6}$. By using these methods some authors concluded that debonding starts before yielding, in deformations near $1 \%$ for polypropylene. Debonding can be evaluated with a derivative plot of the stress-strain curve. As we discussed later debonding leads to the formation of shear bands and to the reduction of the stiffness of the matrix, so the derivative plot should present a discontinuity in the point that debonding starts ${ }^{22}$. This phenomenon is called stress softening ${ }^{21}$.

$$
\left(\frac{\Delta V}{V_{o}}\right)_{C}=\left(\frac{\Delta V}{V_{o}}\right)_{M}(1-\phi)+\left(\frac{\Delta V}{V_{o}}\right)_{V}
$$

The main condition to achieve the desired performance of the nanocomposites is the dispersion of the nanoparticles. This can be a difficulty problem to overcome due to the strong tendency of agglomeration of the nanoparticles, which can be explained by their small particle diameter, i.e., high surface energy ${ }^{4,7}$. Many strategies have been used to solve this problem, the most commons are the surface treatment of the nanoparticles in order to reduce the surface energy 


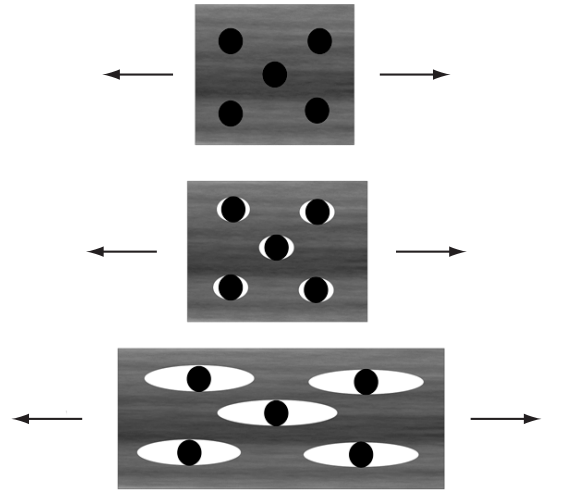

Figure 1. Toughening mechanism with rigid particles. Adapted from Reference number 7.

and in some cases to increase the compatibility with the matrix ${ }^{8}$, and the use of different techniques of mixing, in-situ polymerization, solution and melt processing 9 . Among these techniques, melt processing is considered one of the most interesting methods being the most economical, flexible for formulation and involves compounding and fabrication facilities commonly used in commercial practice 9 Many authors presented different strategies for the incorporation and dispersion of inorganic nanoparticles in polymeric materials in melt state. The best results which mean the higher impact resistance were obtained by using internal mixers coupled to Haake rheometers with extremely long mixing times ${ }^{5,10}$. On the other hand by extrusion process, higher screw speed rotation leads to bad dispersion and impact resistance ${ }^{4}$. So the achievement of good dispersion of the nanoparticles seems to be strongly dependent on the mixing or residence time ${ }^{9}$.

In this context in this work we will present the mechanical properties of polypropylene calcium carbonate nanocomposites with different nanoparticle content which were prepared by melting processing in a co-rotational twin screw extruder that we believe is the most appropriate method, in terms of melting processing, to prepare these nanocomposites. The results will be discussed in terms of nanoparticle dispersion and deformation mechanisms which are initiated by the debonding process. The occurrence of the debonding will be discussed using the derivative plot of stress-strain curves as described later and correlated with the toughening effect of calcium carbonate nanoparticles in PP matrix.

\section{Experimental}

\subsection{Materials}

Polypropylene homopolymer, grade H501-HC (MI = 3,5 g/10 min), was supplied by Braskem Petroquímica, Brazil. Precipitated, calcite, calcium carbonate nanoparticles were supplied by YH-nano, China. The mean diameter of the nanoparticles is between the range of 70-90 $\mathrm{nm}$ and the surface treatment was stearic acid.

\subsection{Preparation of the nanocomposites}

Before extrusion polypropylene and calcium carbonate nanoparticles were dry mixed in the desired compositions. Four compositions of nanocomposites with calcium carbonate content of 3, 5, 7 and $10 \mathrm{wt}$. (\%) were prepared in a co-rotational twin screw extruder machine Werner\&Pfleiderer SZK 30 with screw diameter of $30 \mathrm{~mm}$, $\mathrm{L} / \mathrm{D}=35$, speed rotation of $100 \mathrm{rpm}$ and a high shear screw profile. The temperature profile was $170 / 190 / 190 / 190 / 190 / 195{ }^{\circ} \mathrm{C}$. Tensile test specimens were injected in an Arburg Allrounder $270 \mathrm{~V}$ injection molded machine according ASTM D638, temperature profile was $215 / 220 / 235 / 245 / 250{ }^{\circ} \mathrm{C}$, mold temperature $55{ }^{\circ} \mathrm{C}$, injection pressure 650 bar.

\subsection{Calcium carbonate: morphology and chemical composition of the nanoparticles}

Calcium carbonate nanoparticles were characterized by SEM together with EDS analyzer in a Phillips ${ }^{\circledR}$ XL30 microscope in order to determine the mean particle diameter and the chemical composition of the nanoparticles, and FTIR spectroscopy in order to have some information about the surface treatment of the nanoparticles. FTIR samples were prepared using $\mathrm{KBr}$ in order to make small tablets; the analyses were conducted between $400 \mathrm{a} 4000 \mathrm{~cm}^{-1}$. The analyzes were conducted in a Perkin-Elmer FTIR spectrometer Spectrum 1000.

\subsection{Characterization of the nanocomposites}

Mechanical properties of neat $\mathrm{PP}$ and $\mathrm{PP} / \mathrm{CaCO}_{3}$ nanocomposites were studied in both tensile and impact tests. Tensile tests were conducted in an Instron 5569 universal test machine, with deformation speed of $5 \mathrm{~mm} / \mathrm{min}$. Before testing the samples were conditioned according ASTM D638. The tests were conducted until $150 \%$ of deformation. From the tensile tests we obtained elastic modulus and yield stress. Stress-strain curves were analyzed to estimate the possible occurrence of the debonding process.

Impact tests were conducted at room temperature and in different temperatures in order to determine the brittle-to-ductile transition temperature of all samples. The impact test bars were cut from the tensile specimens. Notching was done on a CEAST automatic notcher and Izod impact tests were conducted following ASTM D256.

\section{Results}

\subsection{Morphology, chemical composition and surface treatment of the nanoparticles}

Figure 2 shows the morphology of the nanoparticles obtained from SEM analyzes. From the results it is possible to say that most of the nanoparticles has diameter in the range of 70-90 $\mathrm{nm}$. Moreover, the nanoparticles have a strong tendency to form agglomerates due to their high surface energy which is a result of the small particle size.

EDS analyzes showed the presence of a little amount of silica in calcium carbonatenanoparticles (Figure 3a), which can be attributed to residue from the production process of calcium carbonate nanoparticles, that has the limestone as raw material ${ }^{11}$. Figure $3 \mathrm{~b}$ presents the FTIR spectra of calcium carbonate nanoparticles. Two bands in wavelengths of 2915 e $2856 \mathrm{~cm}^{-1}$ can be attributed to $-\mathrm{CH}_{2}$ groups probably referred to the surface treatment of the nanoparticles ${ }^{12}$, which has the main function of avoid agglomeration of the nanoparticles but can be used to increase polymer/particle compatibility ${ }^{3}$.

\subsection{Mechanical properties of neat PP and the nanocomposites}

\subsubsection{Tensile mechanical behavior}

Calcium carbonate nanoparticles were incorporated to PP homopolymer in order to achieve better impact resistance and reinforcement of the matrix, so it is convenient to study the stress-strain behavior of neat $\mathrm{PP}$ and $\mathrm{PP} / \mathrm{CaCO}_{3}$ nanocomposites. Moreover the analysis of the tensile mechanical properties, yield stress and elastic modulus, can be related to nanoparticle dispersion, and the analyzes of the stress-strain curves can give some information about the toughening mechanism involved in the incorporation of calcium carbonate nanoparticles in PP matrix. In this context Figure 4 presents 


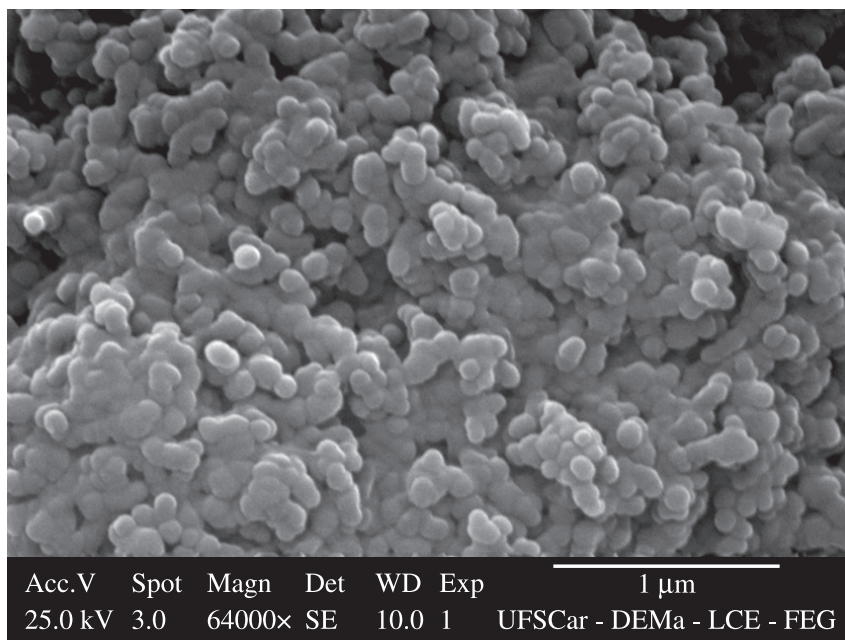

Figure 2. Morphology of calcium carbonate nanoparticles used in this work.

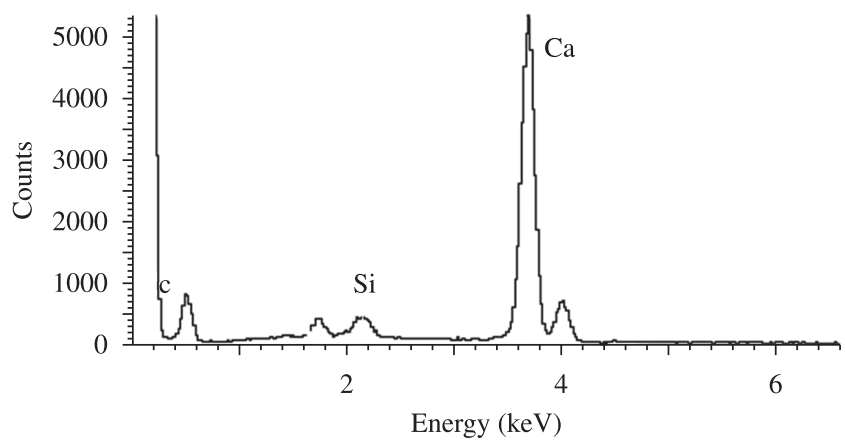

(a)

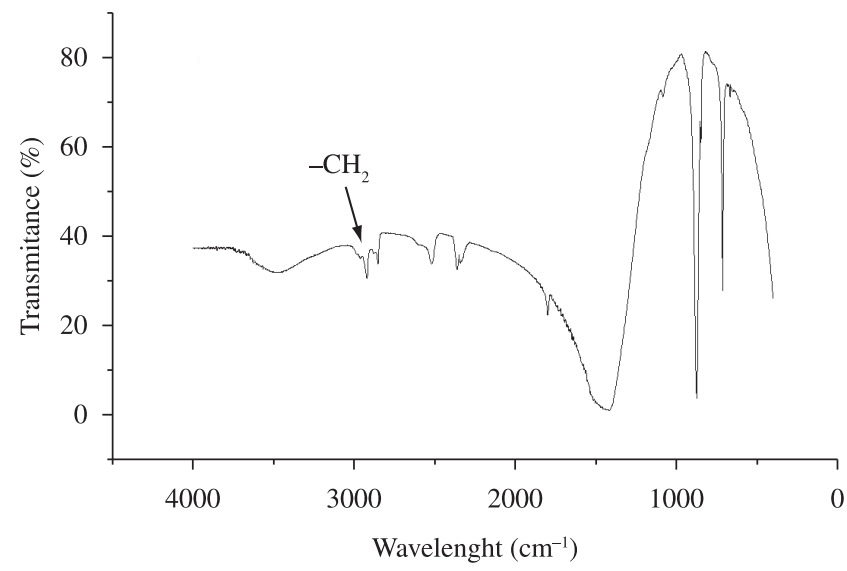

(b)

Figure 3. a) EDS and b) FTIR results of calcium carbonate nanoparticles.

the stress-strain curves of neat $\mathrm{PP}$ and $\mathrm{PP} / \mathrm{CaCO}_{3}$ nanocomposites. A simple analysis of the curves in Figure 4 shows that both elastic modulus and yield stress were increased with the incorporation of nanoparticles, this confirms the reinforcement effect of calcium carbonate nanoparticles in PP matrix ${ }^{13}$.

From Table 1 we can observe a great increase in elastic modulus with the addition of $3 \mathrm{wt}$. (\%) of $\mathrm{CaCO}_{3}$ nanoparticles, but the incorporation of larger contents of $\mathrm{CaCO}_{3}$ did not lead to successive increase in this property. A similar result is observed for the yield stress. It was described in the literature that elastic modulus of polymeric

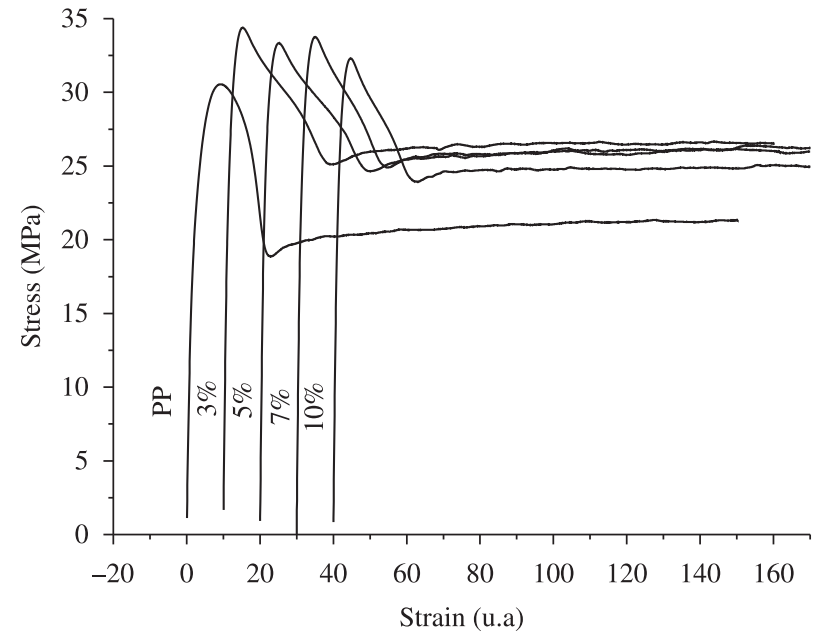

Figure 4. Stress- strain curves of neat $\mathrm{PP}$ and $\mathrm{PP} / \mathrm{CaCO}_{3}$ nanocomposites. Curves were shifted in the $\mathrm{x}$-axis.

Table 1. Mechanical properties of $\mathrm{PP} / \mathrm{CaCO}_{3}$ nanocomposites.

\begin{tabular}{lccc}
\hline Sample & $\begin{array}{c}\text { Yield stress } \\
(\mathrm{MPa})\end{array}$ & $\begin{array}{c}\text { Debonding } \\
\text { stress }(\mathrm{MPa})\end{array}$ & $\begin{array}{c}\text { Elastic } \\
\text { modulus }(\mathrm{GPa})\end{array}$ \\
\hline PP & $31 \pm 0,12$ & 13 & $1,8 \pm 0,2$ \\
PPC3 & $35 \pm 0,12$ & $21 \pm 0,7$ & $2,6 \pm 0,2$ \\
PPC5 & $33 \pm 0,05$ & $20 \pm 0,1$ & $2,6 \pm 0,07$ \\
PPC7 & $33 \pm 0,73$ & $19 \pm 0,6$ & $2,5 \pm 0,13$ \\
PPC10 & $32 \pm 0,01$ & $20 \pm 0,15$ & $2,5 \pm 0,02$ \\
\hline
\end{tabular}

composites depends, just, on surface contact area of the filler and not on its surface treatment ${ }^{13}$. On the other hand yield stress depends on both interfacial strength and surface contact area ${ }^{14,15,16}$. As the surface treatment is the same for all samples, the mechanical properties will be analyzed just in terms of surface contact area, which can be related to the dispersion of nanoparticles in the matrix.

In Figure 5 we compare the experimental data obtained in this work with three models used to predict the elastic modulus of composites. The models used in these work were Halpin Tsai model (Equation 2), which takes into account the aspect ratio of the filler $(\xi)$; the rule of mixtures (Equation 3), which is the Halpin Tsai model for particles with high aspect ratio $(\xi \rightarrow \infty)$ or high surface contact area; and the inverse rule of mixtures (Equation 4), which is the Halpin Tsai model for particles with low aspect ratio $(\xi \rightarrow 0)$ or low surface contact area ${ }^{17}$.

$$
\begin{aligned}
& \frac{E}{E_{m}}=\frac{1+\xi \eta \varphi_{f}}{1-\eta \varphi_{f}} \\
& E=\varphi_{f} E_{f}+\left(1-\varphi_{f}\right) E_{m} \\
& \frac{1}{E}=\frac{\varphi_{f}}{E_{f}}+\frac{\left(1-\varphi_{f}\right)}{E_{m}}
\end{aligned}
$$

From the comparison it is easy to see that the experimental data are higher than the values obtained for all models. The most interesting is that the elastic modulus is higher than that obtained for the rule of mixtures, moreover the distance between the experimental results and the calculated ones decreases with the increase of cal- 


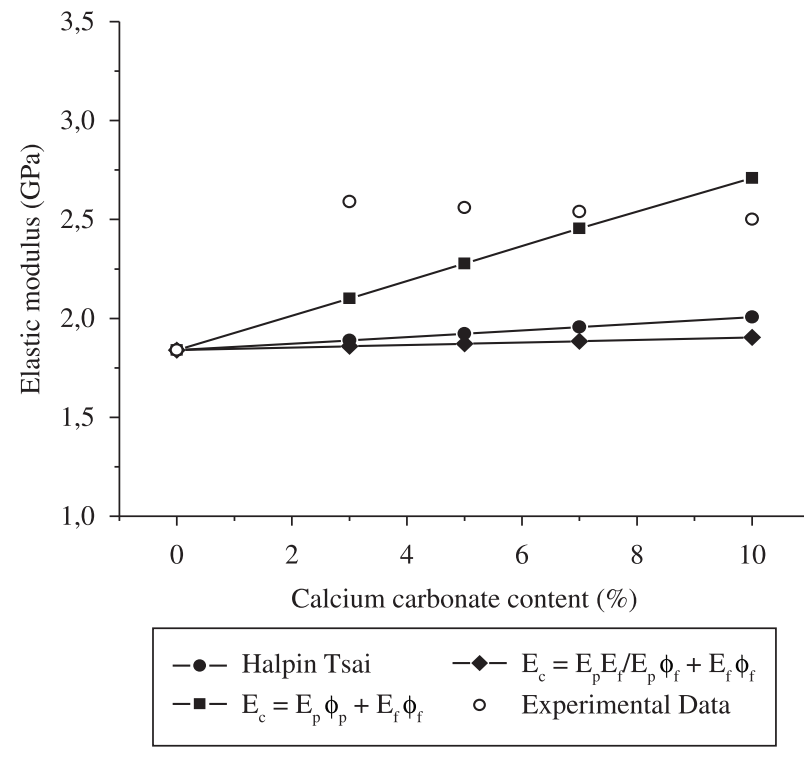

Figure 5. Experimental data of elastic modulus $(\circ)$ as a function of calcium carbonate content compared with models used to predict elastic modulus of composites. (•) Halpin Tsai model (Equation 2), (•) Rule of Mixtures (Equation 3) ( ) Inverse Rule of Mixtures (Equation 4).

cium carbonate content, and when the nanoparticle content reaches $10 \mathrm{wt}$. (\%) the elastic modulus is lower than that predicted for the rule of mixtures. Based on these comments we suggest that calcium carbonate nanoparticles have a strong influence in elastic modulus when incorporated in low contents due to their high surface contact area which is a result of the small particle diameter. When $\mathrm{CaCO}_{3}$ content is increased the nanoparticles tend to form agglomerates that can be described as particles with higher dimensions, smaller surface contact area and smaller effect in the mechanical properties of the matrix.

\subsubsection{Debonding of polymer/filler interface}

As we have already discussed the toughening effect of inorganic fillers in polymeric materials involves basically three aspects; stress concentration, debonding and formation of shear bands. Due to the important role that debonding plays in the toughening process several authors discussed this phenomenon and tried to determine whether it occurs before or at the yielding point ${ }^{6,18,19,20}$. The most accepted theory is that debonding starts before yielding and leads to a reduction in the slope of the stress-strain curves ${ }^{6,18}$. Renner and coworkers used acoustic emission analysis to determine the occurrence of debonding in $\mathrm{PP} / \mathrm{CaCO}_{3}$ composites; they found that debonding starts when the deformation reaches $1 \%{ }^{18}$. Based on the idea that debonding starts before yielding we analyzed the stress-strain curves in deformations inferior to $2 \%$. Figure 6 a shows that there is a tendency of reduction in the slope of the curves when the deformation reaches $1 \%$. Although the results are in accordance with some data in literature it is quite difficult to define the exactly point where this change in the slope occurs because the behavior of the samples is not linear at this point, and it seems difficult to attribute this behavior to debonding since neat PP presents the same change in the slope as the nanocomposites, even though it has no filler to cause debonding.

The results presented in Figure 6a indicate that the behavior of both neat PP and the nanocomposites is due to some intrinsic behavior of the matrix that can be influenced by the incorporation of nanoparticles. A possible explanation for our observations is the stress softening phenomenon, which can be defined as the forma-

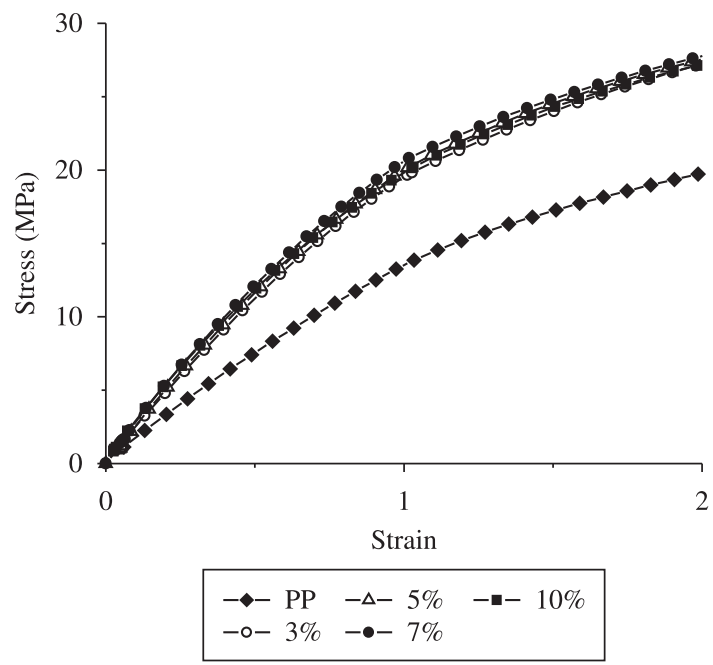

(a)

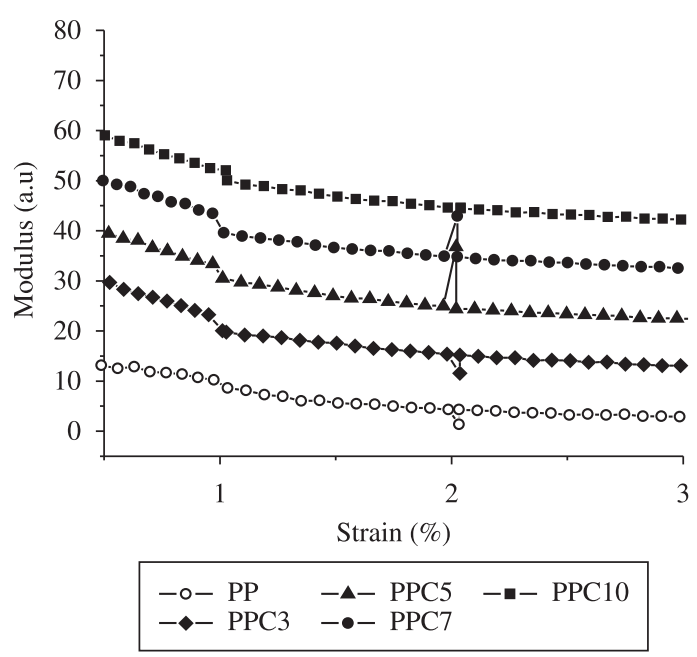

(b)

Figure 6. a) Stress $\times$ Strain curves of neat $P P$ and the nanocomposites for small deformations and $b$ ) Derivative plot of the stress $\times$ strain curves. The symbols were used to differentiate the compositions.

tion of small shear bands called diffuse shear due to the presence of heterogeneity like flaws or stress concentrators in the matrix. Stress softening process leads to a reduction in the stiffness of the matrix inside the shear bands ${ }^{21}$.

Fisa and coworkers showed that both Nylon and PP/glass beads composites present a reduction in the stress/strain relation before the yielding point and attributed this behavior to stress softening ${ }^{22}$.

Figure $6 \mathrm{~b}$ shows the same treatment used by Fisa and coworkers, i.e. the derivative plot of stress-strain curves which can give some information about the occurrence of stress softening and in the case of the nanocomposites information about the debonding process. From the results it is possible to see a step in all the curves when the deformation reaches $1 \%$. This step can be attributed to stress softening, i.e. a reduction in the stiffness of the matrix, or the softening of the matrix. Stress softening can explain why neat PP presents the same behavior of the nanocomposites; the difference is that in neat PP the formation of some diffuse shear is due to flaws that appear during the deformation and in the nanocomposites due to the pres- 


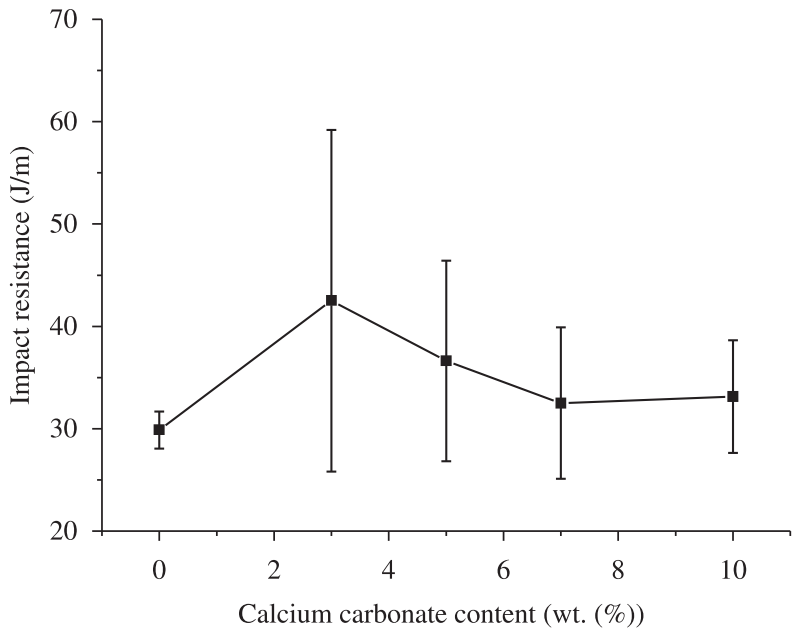

Figure 7. Impact resistance of $\mathrm{PP} / \mathrm{CaCO}_{3}$ nanocomposites as a function of $\mathrm{CaCO}_{3}$ content.

ence of $\mathrm{CaCO}_{3}$ nanoparticles that act as stress concentrators and lead to debonding.

Now that we have more features to assume that debonding starts before yielding in deformations of $1 \%$ we can determine the debonding stress, i.e. the stress when deformation is equal to $1 \%$, that represents both debonding and stress softening in the case of nanocomposites and just stress softening for neat PP. The values of debonding stress presented in Table 1 can be correlated with the elastic modulus data obtained for the nanocomposites. Both properties increase significantly with the incorporation of $3 \mathrm{wt}$. (\%), of calcium carbonate nanoparticles and remain constant with the increase of calcium carbonate content due to the agglomeration of the nanoparticles. Moreover the increase of the debonding stress can be attributed to a strong interaction between polymer and filler caused in this case by the high surface contact area of the nanoparticles, and indicate partial debond of the polymer/filler interface which means that debonding occurs in just one pole of the filler surface ${ }^{19,22,23}$.

\subsubsection{Impact resistance}

In Figure 7 we can see the impact resistance of the nanocomposites as a function of calcium carbonate content at room temperature. Although the mean impact resistance values were increased with the incorporation of calcium carbonate nanoparticles the standard deviation is too high which is an indicative that the working temperature coincides with the brittle-to-ductile transition zone. Zuiderduim and coworkers showed that addition of calcium carbonate particles can decrease the brittle-to-ductile transition temperature $\left(\mathrm{T}_{\mathrm{BD}}\right)$ of polypropylene near to room temperature ${ }^{7}$. If the incorporation of calcium carbonate nanoparticles can achieve the reduction of $\mathrm{T}_{\mathrm{BD}}$ it is important to study the dependence of the impact resistance with temperature.

In Figure 8 we show the relation between impact resistance and temperature for neat PP and the nanocomposites. It is clear that the $\mathrm{T}_{\mathrm{BD}}$ of polypropylene was reduced with the incorporation of calcium carbonate nanoparticles. Brittle-to-ductile transition behavior is a result of the dependence between plastic resistance and temperature; an increase in temperature leads to an increase in chain mobility which causes a reduction in plastic resistance of the material, as the brittle strength which is governed by flaws or imperfections is independent of temperature the result of an increase in temperature is that plastic resistance becomes lower than brittle strength ${ }^{2,24}$. Similar result can be obtained by the incorporation of debonding rigid particles.

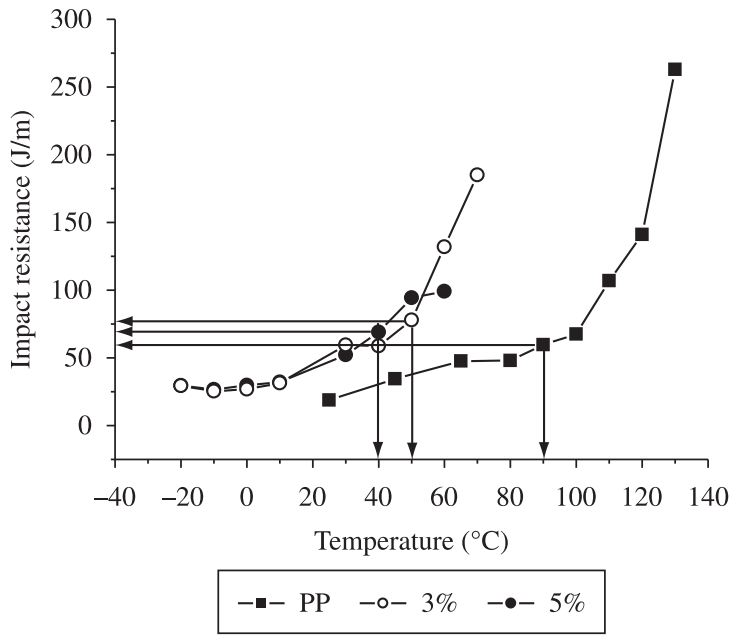

(a)

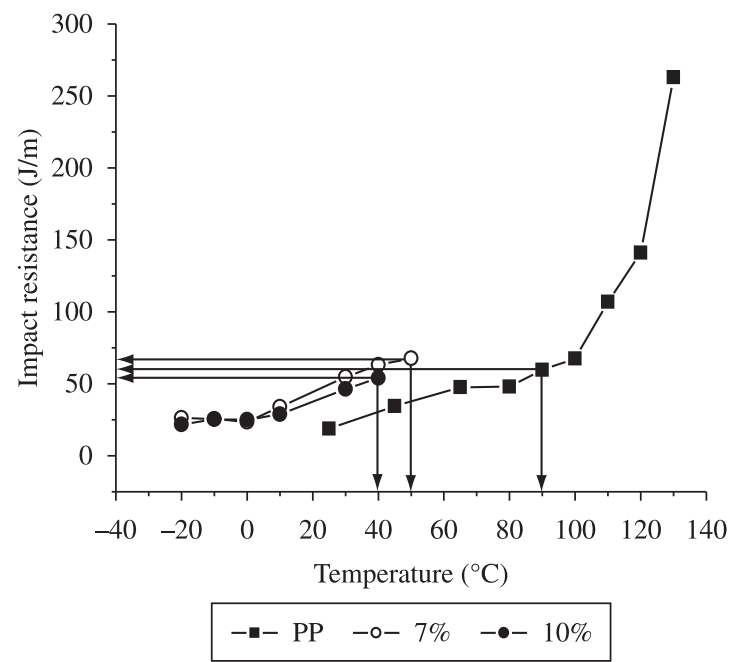

(b)

Figure 8. Impact resistance of neat $\mathrm{PP}$ and $\mathrm{PP} / \mathrm{CaCO}_{3}$ as a function of temperature.

Table 2. Brittle-to-ductile transition temperature and impact resistance before and after transition.

\begin{tabular}{|c|c|c|c|}
\hline Sample & $\mathrm{T}_{\mathrm{DB}}\left({ }^{\circ} \mathrm{C}\right)$ & $\begin{array}{c}\text { Impact Resistance } \\
\text { (Before Transition) } \\
\left({\left.\mathrm{J} . \mathrm{m}^{-1}\right)}\right.\end{array}$ & 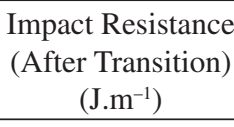 \\
\hline PP & 90 & $18,7 \pm 1,8$ & $59,7 \pm 7,3$ \\
\hline $3 \%$ & 50 & $29,5 \pm 1$ & $96,5 \pm 17,2$ \\
\hline $5 \%$ & 40 & $29,4 \pm 0,7$ & $78 \pm 26$ \\
\hline $7 \%$ & 50 & $26,3 \pm 4,3$ & $67,7 \pm 18$ \\
\hline $10 \%$ & 40 & $25 \pm 2,6$ & $54 \pm 14$ \\
\hline
\end{tabular}

Debonding leads to the formation of shear bands and results in lower plastic resistance. In recent work Chen and coworkers used atomic force microscopy together with DIC (Digital Image Correlation) to show the local strain distribution around silica nanoparticles in Epoxi/ Silica nanocomposites. In their results it is possible to see strain fields around the particles when the deformation reaches $1 \%{ }^{25}$. As the plastic resistance in the nanocomposites is lower than that of neat PP, due 
to debonding and stress softening, their brittle-to-ductile transition temperature is lower than that of neat PP. So the reduction in brittleto-ductile transition temperature can be due to the debonding of the nanoparticles and subsequently reduction of plastic resistance. Table 2 summarizes the results obtained from Figure 7.

\section{Conclusions}

The results obtained in this work evidenced the influence of calcium carbonate nanoparticles in mechanical properties of isotatic polypropylene. Great increases in elastic modulus were obtained with the addition of small content of $\mathrm{CaCO}_{3}$ nanoparticles. The brittle-toductile transition temperature was reduced confirming the toughening effect of calcium carbonate nanoparticles in PP matrix. Tensile mechanical properties seems to be affected by the dispersion of the nanoparticles; small contents of nanoparticles led to an increase in both elastic modulus and yield stress, although the addition of higher contents of nanoparticles did not lead to subsequently increase in these properties that remained constant.

The reduction of brittle-to-ductile transition temperature indicates that plastic resistance of the matrix is reduced with the incorporation of nanoparticles as a result of debonding and stress softening. Finally we suggest that the toughening effect of $\mathrm{CaCO}_{3}$ nanoparticles can be explained by intrinsic deformation mechanisms of polypropylene that are initiated by the debonding of the polymer/particle interface which leads to stress softening.

\section{Acknowledgements}

The authors thank for Braskem and YH-nano for raw materials supplying and for PPG-CEM/DEMa - UFSCar and CAPES for supporting this research.

\section{References}

1. Thio YS, Argon AS, Cohen RE and Weinberg M. Toughening of isotatic polypropylene with $\mathrm{CaCO}_{3}$ particles. Polymer. 2002; 43(13): 3661-3674.

2. Argon AS and Cohen RE. Toughenability of polymers. Polymer. 2003; 44(19): 6013-6032.

3. Tjong SC. Structural and mechanical properties of polymer nanocomposites. Materials Science and Engineering R. 2006; (53): 73-197.

4. Zhang QX, Yu ZZ, Xie XL and Mai YW. Crystallization and impact energy of polypropylene/ $\mathrm{CaCO}_{3}$ nanocomposites with nonionic modifier Polymer. 2004; 45(17): 5985-5994.

5. Chan $\mathrm{CH}, \mathrm{Wu} \mathrm{J}, \mathrm{Li} \mathrm{JX}$ and Cheung YK. Polypropylene/Calcium carbonate nanocomposites. Polymer. 2002; 43(10): 2981-2992.

6. Lazzeri A, Zebarjad SM, Pracella M, Cavalier K and Rosa R. Filler toughening of plastics. Part 1-The effect of surface interactions on physico-mechanical properties and rheological behaviour of ultrafine $\mathrm{CaCO}_{3}$ /HDPE nanocomposites. Polymer. 2005; 46(3): 827-844.

7. Zuiderduim WCJ, Westzaan C, Huétink J and Gaymans RJ. Toughening of polypropylene with calcium carbonate particles. Polymer. 2003; 44(1): 261-275.
8. Rothon RN and Hancock M. In Particulate-Filled Polymer Composites. Rothon RN. (Ed.). England: Longman Scientific \&Technical; 1995. p. $1-42$.

9. Paul DR and Robeson LM. Polymer nanotechnology: Nanocomposites. Polymer. 2008; 49(15): 3187-3204.

10. Lin $\mathrm{Y}$, Chen $\mathrm{H}$, Chan $\mathrm{CM}$ and Wu J. High Impact Toughness Polypropylene/ $\mathrm{CaCO}_{3}$ Nanocomposites and the Toughening Mechanism. Macromolecules. 2008; 41(23): 9204-9213.

11. Solvay Precipitated Calcium Carbonate. Available from: http://www. solvaypcc.com. Access in: 18 March 2009.

12. Wan W, Yu D, Xie Y, Guo X, Zhou W and Cao J. Effects of Nanoparticle Treatment and Mechanical properties of Polypropylene/Calcium Carbonate Nanocomposites. Journal of Applied Polymer Science. 2006; (102): 3480-3488.

13. Laura DM, Keskkula H, Barlow JW and Paul DR. Effect of glass fiber surface chemistry on the mechanical properties of glass fiber reinforced, rubber-toughened nylon 6. Polymer. 2002; 43(17): 4673-4687.

14. Szazdi L, Pozsgay A and Pukanszky B. Factors and processes influencing the reinforcing effect of layered silicates in polymer nanocomposites. European Polymer Journal. 2007; 43(2): 345-359.

15. Sun S, Li C, Zhang L, Du HL and Burnnel-Gray JS. Effects of surface modification of fumed silica on interfacial structures and mechanical properties of poly (vinyl chloride) composites. European Polymer Journal. 2006; 42(7): 1643-1652.

16. Turksányi B, Pukanszky B and Tüdõs F. Composites dependence of tensile yield stress in filled polymers. Journal of Material Science Letters. 1988; (7): 160-162.

17. Fornes TD and Paul DR. Modeling properties of nylon 6/clay nanocomposites using composite theories. Polymer. 2003; 44(17): 4993-5013.

18. Renner K, Yang MS, Móczó J, Choi HJ and Pukanszky . Analysis of the debonding process in polypropylene model composites. European Polymer Journal. 2005; 41(11): 2520-2529.

19. Kraus R, Wilke W, Zhuk A, Luzinov I, Minko S and Voronov A. Investigation of debonding processes in particle-filled polymer materials by acoustic emission: Part I Acoustic emission and debonding stress. Journal of Material Science. 1997; 32(16): 4397-4403.

20. Pukánszky B, Es VM, Maurer FHJ and Vörös G. Micromechanical deformations in particulate filled thermoplastics: volume strain measurements. Journal of Material Science. 1994; 29(9): 2350-2358.

21. Bucknal CB. Toughened Plastics. London: Applied Science Publishers LTD; 1977.

22. Fisa D and Meddad A. Strain Behavior and Tensile Dilatometry of Glass Bead-Filled Polypropylene Polyamide 6. Journal of Applied Polymer Science. 1997; 64(4): 653-665.

23. Kraus R, Wilke W, Zhuk A, Luzinov I, Minko S and Voronov A. Investigation of debonding processes in particle-filled polymer materials by acoustic emission: Part II Acoustic emission amplitude and energy release by debonding. Journal of Material Science. 1997; 32(16): 4405-4410.

24. Galeski A. Strength and toughness of crystalline polymer systems. Progress in Polymer Science. 2003; 28(12): 1643-1699.

25. Chen Q, Chasiotis I, Chen C and Roy A. Nanoscale and effective mechanical behavior and fracture of silica nanocomposites. Composites Science and Technology. 2008; 68(15-16): 3137-3144. 